\title{
Verbal abuse facing Saudi nurses during internship program
}

\author{
Maram Banakhar, Maha Alzahrani, Amani Omar Essa, Asal Fathi Al-dhahry, Rahma Farooq Batwa, Renan Suliman \\ Salem \\ Faculty of Nursing, King AbdulAziz University, Saudi Arabia
}

Received: July 31, 2021

Accepted: October 8, 2021

Online Published: November 11, 2021

DOI: $10.5430 /$ jnep.v12n3p75

URL: https://doi.org/10.5430/jnep.v12n3p75

\begin{abstract}
Background: Verbal abuse, in the context of workplace violence, is increasing, with nurses at high liability of being subjected to it since they are the first line of care delivery. This phenomenon is now receiving greater recognition due to its negative impact on nurses. This study aims to assess the prevalence of verbal abuse faced by Saudi nursing intern students in Jeddah, Saudi Arabia. Methods: A cross-sectional study was conducted via a modified online questionnaire completed by Saudi intern nurses in Jeddah in March 2020. Descriptive statistical analysis was executed using statistical software SPSS Version 21.

Results: From a total of 132 nurses, 94 participants met the study criteria. The findings show that 39.4\% of Saudi intern nurses have experienced verbal abuse. The common perpetrators are patient/client (73\%) and other staff members (73\%), followed by patients' relatives (45.9\%). $48.6 \%$ of the participants did not report incidences of verbal abuse, commonly citing fear of the negative consequences $(51.4 \%)$ and not knowing who to report it to (45.9\%). A significant relation between working night shifts ( $6 \mathrm{pm}$ to $7 \mathrm{am}$ ) and being verbally abused was found.

Conclusions: Saudi nursing interns are vulnerable to verbal abuse. This study's results highlight the possible risk to nursing interns, which may be diminished by modifying perceptions of verbal abuse and by clarifying the rules and regulations for both nursing interns and suspected perpetrators. We recommend future studies of verbal abuse are conducted in larger groups of nurses across different provinces in Saudi Arabia.
\end{abstract}

Key Words: Nursing internship, Verbal abuse, Nursing, Workplace violence, Saudi nurses, Nursing students

\section{INTRODUCTION}

\subsection{Background}

Violence in the workplace is an augmenting global phenomenon. It is considered a challenge for health care providers, especially nurses, as nurses are the first line in delivering patient care. The International Labour Office (ILO), International Council of Nurses (ICN), World Health Organization (WHO), and Public Services International (PSI) established a joint program that defined workplace violence as "Incidents where the staff is abused, threatened, or as- saulted in the circumstances related to their work including commuting to and from work, involving an explicit or implicit challenge to their safety, well-being or health". [1]

Moreover, workplace violence is categorized as physical violence (i.e., violence involving physical contact, such as beating, kicking, slapping, and stabbing), verbal abuse (mistreatment through words or tone, such as disparagement and disrespect), threats (promised use of physical or psychological force resulting in fear of negative consequences), bullying (repeated offensive behaviors that attempt to humiliate an

*Correspondence: Maha Alzahrani; Email: malzahra@villanova.edu; Address: Faculty of Nursing, King AbdulAziz University, Saudi Arabia. 
individual) and sexual harassment. ${ }^{[2]}$ However, verbal abuse was the most frequently reported form of violence faced by nurses since it is an initial phase of subsequent physical violence and bullying/mobbing. ${ }^{[3-5]}$

Concerning the incidence of verbal abuse, a Malaysian study has shown that $70.6 \%$ of nurses have experienced verbal abuse. ${ }^{[5]}$ Likewise, many studies conducted in China, ${ }^{[6,7]}$ Nepal, ${ }^{[8]}$ South Korea ${ }^{[4]}$ and Turkey, ${ }^{[9]}$ revealed that incidences of verbal abuse are rising. Additionally, the latest Saudi studies have found that approximately three out of ten nurses (30.7\%) have experienced verbal abuse. ${ }^{[10]} \mathrm{A}$ study conducted in South Korea showed a high prevalence of verbal abuse in the workplace among nurses, indicating that investigation should be directed towards the demands of nurses at work and hostility. $74.3 \%$ of the nurses had experienced at least one type of verbal abuse from their nursing colleagues during a three-month period. This result reveals that verbal abuse towards nurses in the workplace is a frequent occurrence and may negatively affect their job performance. ${ }^{[11]}$ Another study conducted in Jordan noted that the more worried nurses were about violence at work, the more likely they were to experience physical and verbal abuse, with the prevalence of verbal abuse in Jordan toward nurses being 67.8\%. ${ }^{[12]}$ Additionally, a further two studies demonstrated a relationship between gender and incidence of verbal abuse, revealing that female nurses were more at risk of experiencing verbal abuse. ${ }^{[12,13]}$ On the other hand, a study conducted in Saudi Arabia found that more male nurses had experienced verbal abuse than females. ${ }^{[14]}$ Years of experience was also associated with exposure to verbal abuse, with recent studies reporting that nurses with between one year to less than three years of experience, and newly licensed nurses, have significant exposure to verbal abuse. ${ }^{[4,11]}$ Nursing interns are also frequently exposed to verbal abuse. A recent study conducted in Saudi Arabia found that 55\% of nursing interns had been exposed to one type of verbal abuse at least once a year, and this adversely affected them psychologically, causing anxiety, depression, and stress. ${ }^{[15]}$

In addition to the above, a study in Saudi Arabia showed that in relation to misunderstandings and communication barriers between nurses and patients, more nurses who had experienced workplace violence viewed this as verbal abuse and found it to be a serious issue in relation to those who had not experienced workplace violence. ${ }^{[3]}$ This issue is becoming more prevalent in hospitals in China, ${ }^{[6,7]}$ Korea, ${ }^{[4]} \mathrm{Nepal},{ }^{[8]}$ and Turkey. ${ }^{[9]}$ Several studies have reported that patients' relatives and patients themselves were the most frequent perpetrators of verbal abuse. ${ }^{[8,12,13]}$ Conversely, other studies have shown that verbal abuse was most exhibited by physicians. ${ }^{[3,11]}$ A study conducted in Jordan indicated that the most frequent type of verbal abuse by patients' relatives was shouting and swearing. ${ }^{[13]}$ While a further study conducted in Saudi Arabia described that deliberately ignoring the nurse was the most frequent form of verbal abuse. ${ }^{[14]}$ Consequently, given the magnitude of the issue and the fact that there is limited data on verbal abuse toward nursing interns in Saudi Arabia, this study aims to examine the present status of verbal abuse experienced among Saudi nursing interns.

Verbal abuse has a negative influence on both experienced nurses and newly licensed nurses alike, such as decreased job satisfaction, increased burnout, reduced commitment to the workplace, and altered job performance. ${ }^{[4]}$ Over half of abused nurses have considered leaving nursing and feel their quality of work has decreased because of the abuse. ${ }^{[13]}$ These negative consequences could ultimately affect patient safety and the quality of patient care. ${ }^{[7]}$ Nurses working in the Emergency department are more vulnerable to exposure to verbal abuse than nurses in other departments. ${ }^{[10,16]} \mathrm{A}$ better nursing environment, however, is related to lower risks of physical and non-physical abuse. ${ }^{[15]}$

In another study, higher physical violence and hostility was markedly linked to a greater experience of verbal abuse. ${ }^{[11]}$ A study in Hong Kong reported that depression, anxiety, and stress were strong associations regarding workplace violence. ${ }^{[16]}$ There is a major negative association between workplace violence exposure (WPV) and nurse's health outcomes, difficulty with family relationships, difficulty sleeping, low self-worth, appetite problems, and work stress experience. ${ }^{[6,9]}$ Elevating the stress of nurses caused by WPV can lead to poor quality of sleep and adversely affect physical and psychological well-being. ${ }^{[3]}$ Another study found that verbal abuse affects the morale and work satisfaction of nurses, increases burnout, decreases job performance, and reduces commitment to the organization. ${ }^{[5]}$ A study in Ghana showed that nurses who have been exposed to verbal abuse were less satisfied with their job. Additionally, a study in Turkey stated that abuse impacted nurses' relationships and triggered thoughts of leaving nursing. ${ }^{[10,14]}$ Reporting the incidence of verbal abuse was ignored as it was considered unproductive for the majority of nurses who participated in Alomari and Ahmed's studies. ${ }^{[13,15]}$ Additionally, Saudi studies have paid particular attention to cultural diversity with regard to nurses of different nationalities, which increases the risk of interpersonal conflict when non-Arab nurses are dealing with patients and families who don't speak English, which can create miscommunications and has been cited as a cause of verbal abuse toward nurses. ${ }^{[3]}$

Verbal abuse is a major concern faced by nurses with a high occupational prevalence, especially in the health care sector. 
This leads to several consequences such as reduced commitment to the workplace, stress, and job dissatisfaction. Hence, these negative consequences could ultimately affect patient safety and the quality of patient care. ${ }^{[4]}$ Although, a small number of studies have been conducted among nursing interns in Saudi Arabia, no study has specifically focused on Saudi nursing interns in Jeddah. For this reason, this study was conducted to address this issue in the context of Saudi Arabia, as the researchers hope to provide the necessary baseline data for future articles due to the scarcity of studies regarding this issue in Saudi Arabia.

\subsection{Study aim}

To assess the prevalence rate of verbal abuse faced by Saudi nursing interns undertaking an internship programme in Jeddah hospitals.

\subsection{Research question}

What is the prevalence rate of verbal abuse faced by Saudi nursing interns in Jeddah, Saudi Arabia?

\section{MAterials AND MethodS}

\subsection{Research design}

A descriptive, cross-sectional design was conducted to assess the prevalence rate of verbal abuse faced by Saudi nursing interns undertaking an internship program in Jeddah hospitals.

\subsection{Study setting}

The participants of this study were Saudi intern nurses who were distributed across several hospitals in Jeddah, Saudi Arabia. These hospitals are King Abdul-Aziz University Hospital, King Faisal Specialist Hospital, and Research Centre, King Fahad Armed Forces Hospital, King Fahad General Hospital, King Abdullah Medical City, King Abdulaziz Medical City(National Guard Hospital), Dr. Soliman Fakeeh Hospital, East Jeddah General Hospital, and Dr. Sulaiman Al Habib Hospital. All Saudi nursing interns from different regions in Saudi Arabia who took their internship in Jeddah Hospitals were enrolled in this study.

\subsection{Sampling}

The target population is Saudi nursing interns from different hospitals in Jeddah, Saudi Arabia, who had completed a minimum of three months of their internship. The sample was collected between March 1st and March 30th, 2020. Participants were selected under the following inclusion criteria: Saudi nursing students from both genders, of 20 years old and above, who graduated from the School of Nursing and have completed a minimum of three months of their internship at different hospitals in Jeddah. The exclusion criteria included: non-Saudi nursing interns, nurses who were taking

Published by Sciedu Press their internship year outside Jeddah city, and nursing interns who had completed their internship period.

\subsection{Tool}

The instrument used in this study is a modified questionnaire developed by the Joint Programme on Workplace Violence in the Health sectors of the WHO, the ILO, the ICN, and the PSI. ${ }^{[1]}$ The questionnaire has two parts; the first includes personal and workplace data (12 items) and the second part concerns verbal abuse (12 items). The first question in the second part asks whether the respondent has been verbally abused in the workplace from the beginning of their internship, asking if yes, how often, followed by questions concerning the characteristics of the abuse, how it was dealt with, the consequences of the recent incident, and the participant's response to the stressful event. If the participants had never experienced verbal abuse violence, they only completed the first part of the survey and did not respond to the second part. Some parts of the original questionnaire were omitted because they did not conform with the objectives of this study.

\subsection{Data collection procedure}

After obtaining ethical approval, the data collection began using a snowball sampling technique via an online questionnaire. The survey was initially sent via text message to nursing interns studying at King Abdulaziz University and taking their internship year in different hospitals in Jeddah, as it was easy to contact them through the clinical affairs office for intern students. The clinical affairs office were then asked to distribute the questionnaire to the interns in their hospitals. The survey was also posted on many social media groups specifically for nurses from different hospitals in Saudi Arabia.

\subsection{Data analysis}

Statistical analysis was completed using SPSS version 21. Mean and standard deviation were calculated to describe continuous variables, while numbers and frequencies were used for categorical variables. The association between categorical variables was tested by using the Chi-square test $\mathrm{A}$, with $p$-value $<.05$ considered significant.

\subsection{Ethical considerations}

Ethical approval was agreed by the Faculty of Nursing at King Abdulaziz University. Participants were informed that their participation was voluntary and that their privacy and confidentiality would be respected and protected. There was no monetary incentive to their participation in this study and no reimbursement was provided. There was no financial cost to the participants as a result of taking part in this study. A 
brief introduction to the study objective was given before answering the questionnaire.

\section{Results}

A total of 132 Saudi nursing interns completed the questionnaires, with 94 meeting the study criteria, with a response rate of $72 \%$. Table 1 represents the demographic and workrelated characteristics of the participating Saudi nursing interns. $97.9 \%$ of the Saudi nursing interns were female $(\mathrm{n}=$ $92)$, with $86.2 \%(n=81)$ being single. More than half of the nursing interns $(79.8 \%)$ were working shifts $(n=75)$. The majority of the participants $(63.8 \%)$ had completed more than six months of internship, while $21.3 \%$ and $14 \%$ of the nursing interns had completed less than seven months and less than four months of the programme, respectively. 34\% of the participants gave a neutral response when questioned about their concerns about workplace violence. The majority of the participants $(54.3 \%)$ reported that procedures for reporting workplace violence were in place, with more than half $(62.7 \%)$ stating that they knew how to use them, while $37.3 \%$ reported that they did not know how to use the procedures. The majority of the participants (70.2\%) had been encouraged to report workplace violence, with the encouragement coming mostly from management (63.1\%).

Table 2 indicates that $39.4 \%$ of the participants experienced verbal abuse as $100 \%$ were female. A total of $33 \%$ work shifts between 6 pm-7 am. The results show a significant relationship, $p<.05$, between working shifts between $6 \mathrm{pm}$ to 7 am and being verbal abused.

Table 3 shows that $56.8 \%$ of Saudi nursing interns have been verbally abused sometimes, while $35.1 \%$ have been abused just once. Regarding the abusers, the most reported sources were the patient/client (73\%) and other staff members $(73 \%)$, relatives of the patient/client $(45.9 \%)$, management/supervisor (32.4\%), and the general public $(24.3 \%)$. With regard to the gender of the abusers, $54.1 \%$ were female and $32.4 \%$ male $15.5 \%$ respectively. Most verbal abuse $(93.3 \%)$ took place inside health institutions. The participants responded to the verbal abuse in a number of different ways as follows: told a colleague (78.4\%), took action $(70.3 \%)$, told friends/family (67.6\%), sought counseling (48.6\%), told the person to stop (40.5\%), pursued prosecution (27\%), tried to pretend it never happened $(27 \%)$, and reported it to a senior staff member $(27 \%)$. $81.1 \%$ thought the incident could be prevented.

Figure 1 shows the response of Saudi nursing interns to this stressful event with regard to how bothered they have been by it, if they have avoided thinking about or talking about the abuse, being "super-alert" as a result of it, and feeling like everything they did after it was an effort.

Table 1. Demographics and work related characteristics

\begin{tabular}{|c|c|}
\hline Demographic data & $\mathbf{N}(\%)$ \\
\hline \multicolumn{2}{|l|}{ Gender } \\
\hline Female & $92(97.9)$ \\
\hline Male & $2(2.1)$ \\
\hline \multicolumn{2}{|l|}{ Nationality } \\
\hline Saudi & $94(100)$ \\
\hline \multicolumn{2}{|l|}{ Marital Status } \\
\hline Single & $81(86.2)$ \\
\hline Married & 11 (11.7) \\
\hline Divorced & $2(2.1)$ \\
\hline \multicolumn{2}{|l|}{ Internship duration } \\
\hline 3-1 months & 14 (14.9) \\
\hline 6-4 months & $20(21.3)$ \\
\hline 9-7 months & $35(37.2)$ \\
\hline 10-12 months & $25(26.6)$ \\
\hline \multicolumn{2}{|l|}{ Work in shifts } \\
\hline Yes & 75 (79.8) \\
\hline No & $19(20.2)$ \\
\hline \multicolumn{2}{|l|}{ Work between $6 \mathrm{pm}$ to 7 am } \\
\hline Yes & $69(73.4)$ \\
\hline No & $25(26.6)$ \\
\hline \multicolumn{2}{|l|}{ Number of staff presented in work } \\
\hline zero & $2(2.1)$ \\
\hline 5-1 & $34(36.2)$ \\
\hline $10-6$ & $31(33)$ \\
\hline $15-11$ & $20(21.3)$ \\
\hline Over 15 & $7(7.4)$ \\
\hline \multicolumn{2}{|l|}{ Worried about violence in current workplace } \\
\hline Not at all & $24(25.5)$ \\
\hline More to no & $24(25.5)$ \\
\hline Neutral & $32(34)$ \\
\hline More to yes & $10(10.6)$ \\
\hline Yes, very & $4(4.3)$ \\
\hline \multicolumn{2}{|l|}{ Procedure for reporting violence in workplace } \\
\hline Yes; & $51(54.3)$ \\
\hline Know how to use them ( yes , no) & 19 (37.3), 32 (62.7) \\
\hline No & $15(16)$ \\
\hline Don't know & $28(29.8)$ \\
\hline \multicolumn{2}{|l|}{ Encouragement to report workplace violence } \\
\hline Yes; by : & $66(70.2)$ \\
\hline Management/employer & $41(63.1)$ \\
\hline Own family/friends & $6(9.2)$ \\
\hline Colleagues & $11(16.9)$ \\
\hline Association & $3(4.6)$ \\
\hline Association & $4(6.2)$ \\
\hline No & $28(29.8)$ \\
\hline \multicolumn{2}{|l|}{ Practicing hospital } \\
\hline King Abdul-Aziz University Hospital & $22(23.4)$ \\
\hline King Faisal Specialist Hospital and Research Center & $14(14.9)$ \\
\hline King Fahad Armed Forces Hospital & 30 (31.9) \\
\hline King Fahad General Hospital & $6(6.4)$ \\
\hline King Abdullah medical city & $2(2.1)$ \\
\hline King Abdulaziz medical city & $15(16)$ \\
\hline Dr Soliman Fakeeh Hospital & $3(3.2)$ \\
\hline East Jeddah General Hospital & $1(1.1)$ \\
\hline Dr Sulaiman Al Habib Hospital & $1(1.1)$ \\
\hline
\end{tabular}

Table 4 indicates that $24.3 \%$ of participants answered yes to action taken to investigate the causes of abuse. Of those who answered yes, $100 \%$ responded that the action was taken by their management/employer with $33.3 \%$ also stating that 
action was taken by a community group. Regarding the consequences for the abuser, $88.9 \%$ received a verbal warning, with $44.4 \%$ being reported to the police and $33.3 \%$ of aggressors being prosecuted. $54.1 \%$ of the participants reported that their employer/supervisor had offered them an opportunity to speak about/report it, with $32.4 \%$ being offered counseling.

Table 2. Characteristics of verbally abused Saudi nursing interns

\begin{tabular}{ll}
\hline Characteristics & N (\%) \\
\hline Verbally abused & $37(39.4)$ \\
Yes & $57(60.6)$ \\
No & $37(100)$ \\
Female & $0(0)$ \\
Male & $33(89.2)$ \\
Working in shifts & $p=.117$ \\
& $33(89.2)$ \\
Work between 6pm to 7am & $p=.011$ \\
\hline
\end{tabular}

\section{Discussion}

The aim of this study was to determine the prevalence of verbal abuse among Saudi nursing interns at different hospitals in Jeddah. The study revealed that the prevalence of verbal abuse is lower than in previous studies. However, a small number of studies conducted in Saudi Arabia have shown that the prevalence of verbal abuse was similar to the current study result, ${ }^{[3,10]}$ while a study in the eastern province of Saudi Arabia reported that more than half of nursing interns had been exposed to one type of verbal abuse at least once a year. ${ }^{[14]}$ With regard to other middle eastern studies, this compares to $84.5 \%$ in Turkey, ${ }^{[9]} 60 \%$ in Lebanon, ${ }^{[17]}$ and $37.1 \%$ in Jordan. ${ }^{[13]}$ These findings are consistent with international studies that have reflected a high percentage of the prevalence of verbal abuse in China, ${ }^{[7]}$ South Korea, ${ }^{[11]}$ South Africa, and Thailand, ${ }^{[18]}$ ranging from $47.7 \%$ to $79.33 \%$. A possible explanation for this result is that this study only examined verbal abuse while the majority of the previous studies examined workplace violence as a whole. Additionally, the decline in the incidence of verbal abuse promotes the notion of Saudi Arabia's culture and religion. Also, lately, there is a rising awareness of verbal abuse, and new regulations with recent rules to incite the perpetrator to limit the abuse. Another possible explanation is the existence of a clear system for reporting violence in the workplace and encouragement to report it. The majority of the participants (70\%) answered yes regarding the presence of a procedure for reporting violence and receiving encouragement from management/employer to do so. This finding is in agreement with other studies in which the majority of nurses $(70.8 \%)$ reported the existence of procedures to report abuse. ${ }^{[10]}$ Moreover, the decrease in concerns about violence by $34 \%$ was neutral in worries about violence in nursing interns was explained by the presence of a reporting system and the encouragement to report incidences of verbal abuse. On the other hand, nurses are subjective in their interpretation of workplace violence; thus, it can be perceived differently. In Alkurashy's study, for example, nurses who had experienced violence defined it as verbal abuse, while those who had not experienced violence perceived it as a physical attack. This may reflect the decline in the percentage of the prevalence of violence reported. ${ }^{[3]}$

Table 3. People and response to verbal abuse event

\begin{tabular}{ll}
\hline Characteristics & N (\%) \\
\hline Often been verbally abused during internship program & \\
Once & $13(35.1)$ \\
Sometimes & $21(56.8)$ \\
All the time & $3(8.1)$ \\
Who verbally abused the & \\
Patient/client & $27(73)$ \\
Staff member & $27(73)$ \\
External colleague/worker & $5(13.5)$ \\
Relatives of patient/client & $17(45.9)$ \\
Management/supervisor & $12(32.4)$ \\
General public & $9(24.3)$ \\
Gender of attacker & \\
Female & $12(32.4)$ \\
Male & $5(13.5)$ \\
Both & $20(54.1)$ \\
Where verbal abuse took place & \\
Inside health institution & $36(97.3)$ \\
Outside (on way to work) & $1(2.7)$ \\
Respond to verbal abuse & \\
Took no action & $26(70.3)$ \\
Told the person to stop & $15(40.5)$ \\
Told friends/family & $25(67.6)$ \\
Told a colleague & $29(78.4)$ \\
Transferred to another position & $9(24.3)$ \\
Sought help from the union & $5(13.5)$ \\
Pursued prosecution & $3(8.1)$ \\
Tried to pretend it never happened & $10(27)$ \\
Sought counseling & $10(27)$ \\
Reported it to a senior staff member & $18(48.6)$ \\
Sought help from the association & $10(27)$ \\
Completed a compensation claim & $8(21.6)$ \\
Completed incident/accident form & $5(13.5)$ \\
Yes incident could be prevented & $30(81.1)$ \\
No & $7(18.9)$ \\
\hline & \\
\hline
\end{tabular}

A further important result of this study is that it was found to be predominantly staff members and patients who are the perpetrators of verbal abuse of nursing interns. This result is contrary to previous studies that found that doctors and nurses' colleagues were the main abusers. ${ }^{[9,12,19-21]}$ The explanation for the high incidence of verbal abuse from doctors and nurses' colleagues is that intern nurses are new in practic- 
ing nursing, so they are less skilled than others and therefore do not have full knowledge of the appropriate equipment and procedures, which may result in doctors and their colleagues becoming irritated and directing abuse at them. ${ }^{[4,22]}$ Additionally, the patients themselves were found to be the primary cause of the event of abuse in these studies. ${ }^{[3,4,10,12,23,24]}$ This could relate to the nature of nurses' work as they are

\section{Since you were abused, how bothered have you been by:}

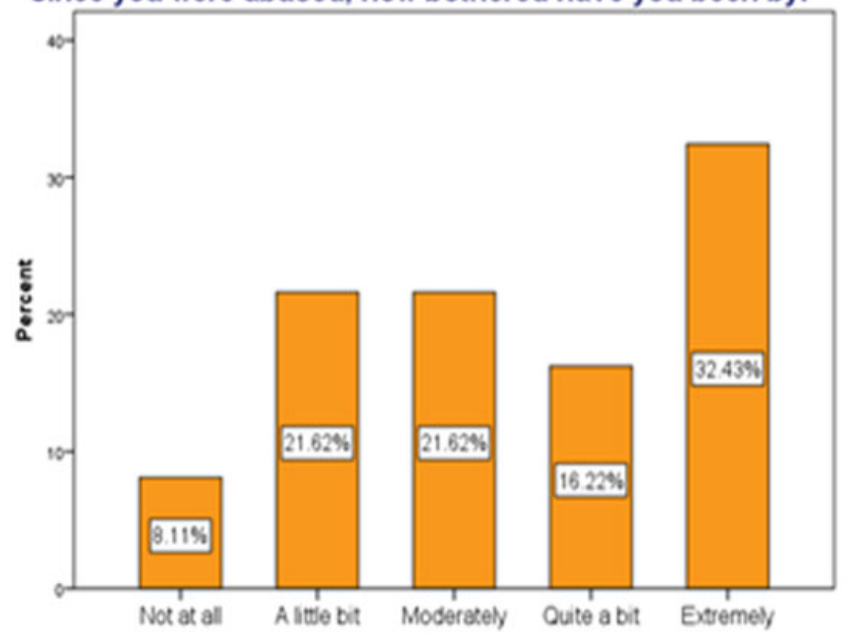

Being "super-alert" or watchful and on guard?

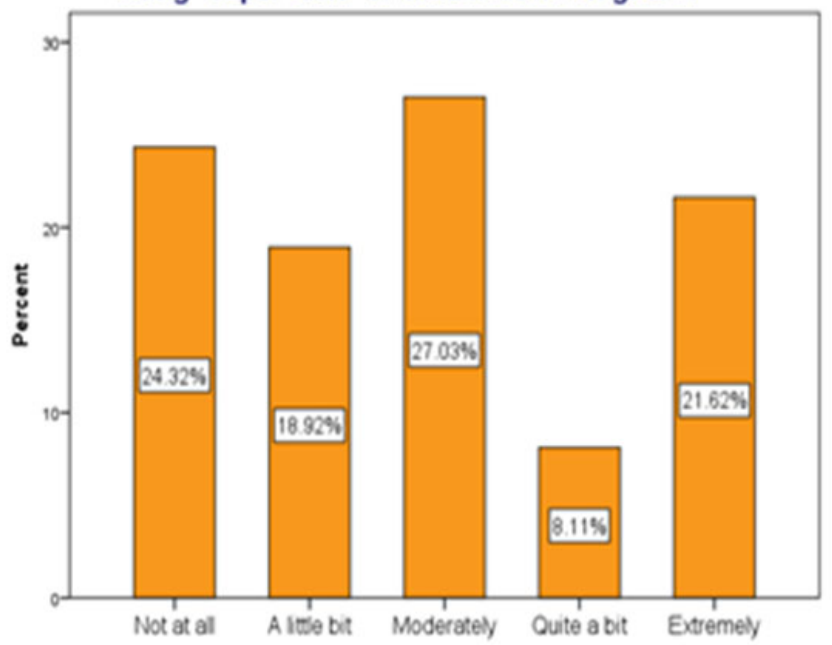

Figure 1. Response to verbal abuse

A significant relationship was reported in this study between working shifts between 6 pm to 7 am and being verbally abused. A possible justification of this result is that these shifts are visiting hours in most of the hospitals, so patient's relatives are included among the perpetrators of verbal abuse. A further justification is that this time of day is typically the patients' rest and sleeping hours, so nurses attempting to provide care at this time can disturb the patient's sleep. Interestingly, the patient's relatives were found to be the second highest perpetrators of abuse in this study. These results the first line in handling patients. It is therefore anticipated that they are more likely to get the blame for delays in, or inadequate provision of, health care. ${ }^{[25]}$ Additionally, patients themselves were often found to be the perpetrators of abuse of intern nurses as they represent a vulnerable and easy target for patients wishing to vent their anger and frustrations about the health service.
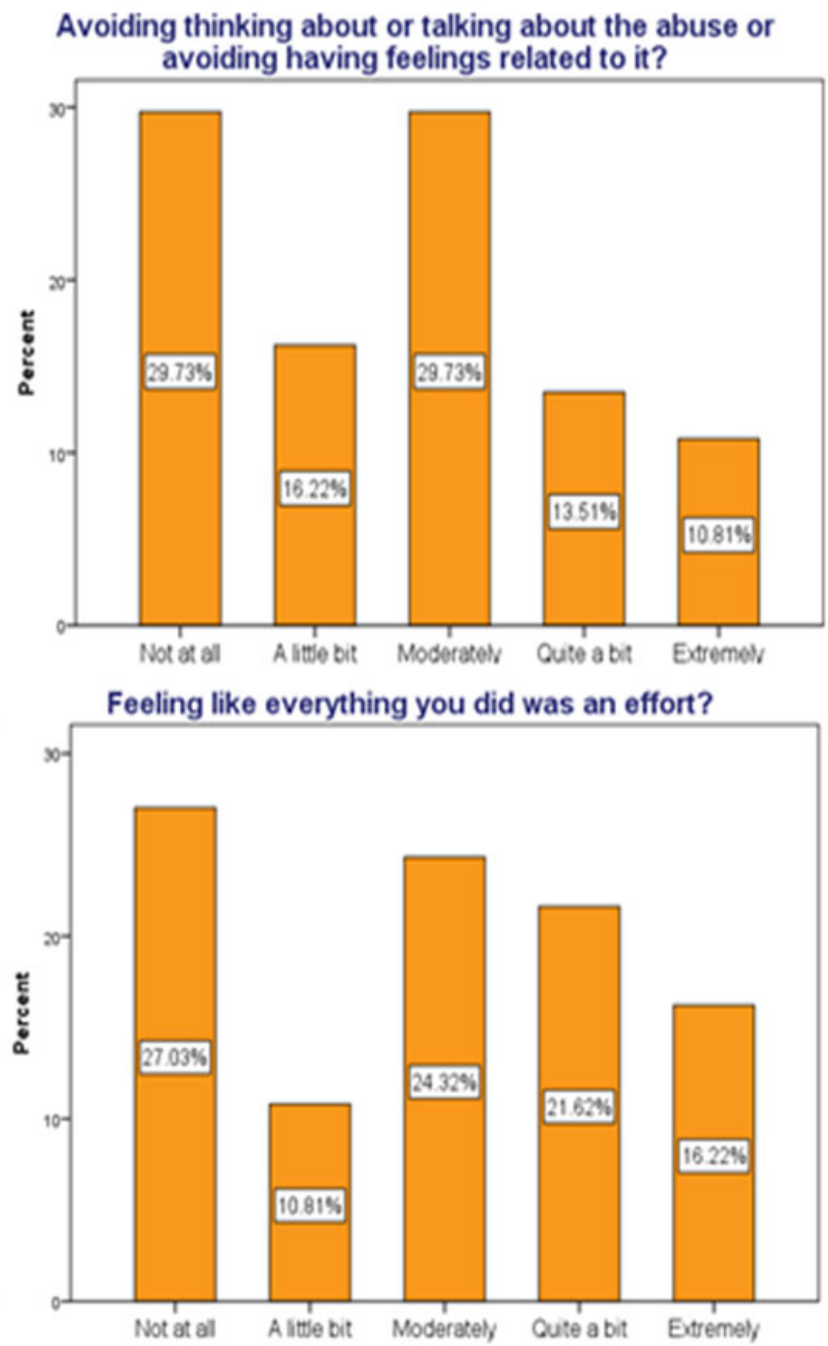

were counter to other studies ${ }^{[7,9,14]}$ that found that verbal abuse occurred more frequently during morning shifts. To the best of our knowledge, no other studies have reported nurses being exposed to verbal abuse most frequently during the night shift.

Moreover, this study demonstrated that incidences of abuse were underreported by Saudi nursing interns. However, this is consistent with the high rates of underreporting of incidents as identified in other studies. ${ }^{[3,8,13]}$ The reasons for not reporting any abuse in this study were cited as being 
afraid of negative consequences, not knowing who to report to, feeling it would be unproductive, feeling it was not important, or feeling ashamed. This was consistent with previous studies which stated that the majority of nurses fail to report incidents of verbal abuse because it is unproductive to do so, ${ }^{[3,13]}$ or because of fear of negative consequences. ${ }^{[8]}$ This may stem from the fact that in the healthcare system, the priority is typically for the patient's rights, and therefore nurses may be afraid of being blamed. Another interpretation is that they might believe the investigation would be an overly lengthy and time-consuming process .In this study, all the participants answered that actions taken as a result of reporting the abuse were taken by management, with some incidences being reporting to the police. This suggests that the participants in this study were fully aware that taking legal action was appropriate in certain cases.

Table 4. Causes, consequences and reasons of not reporting of not reporting the verbal abuse violence

\begin{tabular}{ll}
\hline Characteristics & N (\%) \\
\hline Action taking to investigate the causes of abuse & \\
Yes & $9(24.3)$ \\
No & $18(48.6)$ \\
Don't know & $10(27)$ \\
Yes, by & \\
Management/Employer & $9(100)$ \\
Community group & $3(33.3)$ \\
Union & $2(22.2)$ \\
Police & $2(22.2)$ \\
Association & $2(22.2)$ \\
Yes, the consequence of abuser & \\
Verbal warning issued & $8(88.9)$ \\
Care discontinued & $2(22.2)$ \\
Reported to police & $4(44.4)$ \\
Aggressor prosecuted & $3(33.3)$ \\
Don't know & $2(22.2)$ \\
None & $2(22.2)$ \\
Employer/supervisor offer to provide with & \\
Counseling & $12(32.4)$ \\
Opportunity to speak about/report it & $20(54.1)$ \\
Other support & $15(40.5)$ \\
Satisfied about how the incidence was handled & \\
Not at all & $10(27)$ \\
More to no & $7(18.9)$ \\
Neutral & $16(43.2)$ \\
More to yes & $3(8.1)$ \\
Yes, very & $1(2.7)$ \\
Causes of NOT reporting the incidence to others & \\
It was not important & $14(37.8)$ \\
Afraid of negative consequences & $19(51.4)$ \\
Felt ashamed & $12(32.4)$ \\
Useless & $15(40.5)$ \\
Felt guilty & $11(29.7)$ \\
Did not know who to report to & $17(45.9)$ \\
\hline & \\
& \\
\hline
\end{tabular}

Figure 2 shows how satisfied Saudi intern nurses were with how verbal abuse was handled.

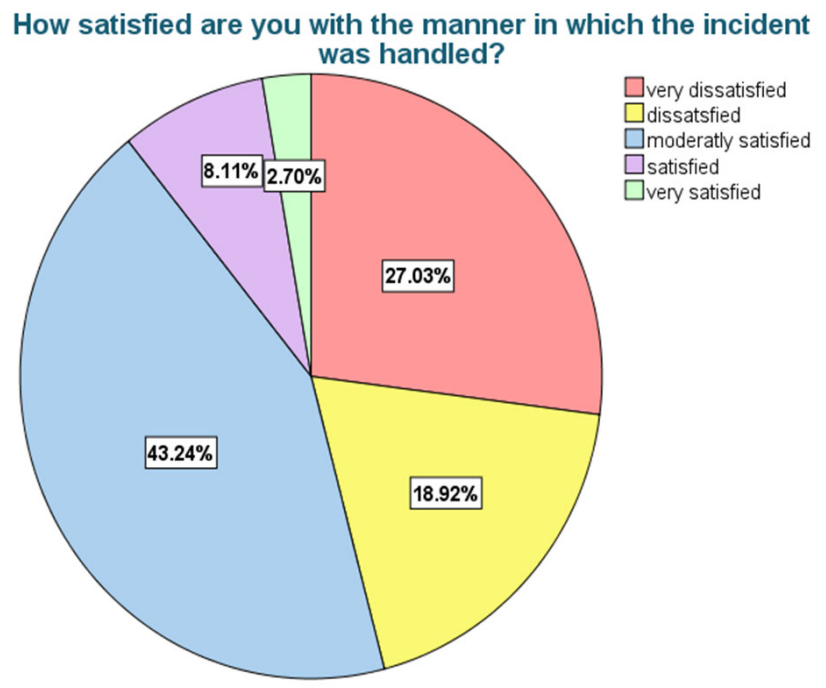

Figure 2. Satisfaction of nursing interns in handling the verbal abuse incident

Contrary to previous studies in which the majority of nurses who were verbally abused had no counseling from the employer/supervisor, ${ }^{[8,10]}$ in this study, the majority of participants revealed that their employer/supervisor offered to provide counseling, and provided opportunities for discussion of the incident. The benefits of providing counseling and opportunities for discussion for nursing interns who are at the beginning of their careers and require further support can be reflected in an increase in work satisfaction, productivity, and mental health and well-being. This is associated in this study with the reported neutrality of nursing interns' satisfaction. This result is considered acceptable in comparison with the previous studies, which revealed the dissatisfaction of nurses. ${ }^{[10]}$ These differences may be explained by the fact that each hospital has its own system for managing violence.

The main limitation of this study is the small sample size, which is not sufficiently representative to generalize the incidence of verbal abuse in Saudi interns in Jeddah, Saudi Arabia. The use of a self-reporting measure is a further limitation of this study as self-reporting measures can be susceptible to social desirability bias. The published literature regarding verbal abuse faced by Saudi nurses during their internship programme is very limited, which caused challenges in comparing results and providing a detailed review of the literature. The final limitation of this study is that the majority of the participants were females, with a very low percentage of males of whom none reported facing verbal abuse.

\section{Implications}

This study has considerable implications for practice and future studies. It is recommended as a means of avoiding 
possible subjectivity in the perceptions of verbal abuse of nursing interns that they should be made familiar with all the relevant policies and the process of incident reporting before beginning their internship. This would assist organizations in increasing awareness and knowledge of workplace violence, particularly verbal abuse, as well as the rules and regulation. It is also recommended that leaders and managers are encouraged to implement an appropriate reporting system requiring mandatory follow-up reviews, enabling nursing interns to report incidents and reassuring them that doing so will not result in any negative consequences. Moreover, organizations should also implement training at the beginning of nursing intern programmes on how to avoid and handle exposure to workplace violence in health care organizations in cooperation with professional orders, as well as offering team-building sessions to reduce the impact of horizontal violence. Additionally, it is important to all nursing colleges to have a policy if any nursing intern exposed or experienced any type of violence during their internship program. A future study with a larger sample size, involving equal numbers of male and female nursing interns across Saudi Arabia, is recommended to establish a reliable percentage of verbal abuse among Saudi nursing interns. Furthermore, more detailed identification and examination of the sources of verbal abuse among nursing interns is recommended. Importantly, for more in-depth and richer data, a qualitative study should be conducted to explore the experience and feelings of Saudi nursing interns when facing this issue, which could help in

\section{REFERENCES}

[1] Joint Programme on Workplace Violence in the Health Sector of the International Labor Office. The International Council of Nurses, The World Health Organization, and the Public Services International.

[2] Boyle MJ, Wallis J. Working towards a definition for workplace violence actions in the health sector. Saf. Health. 2016. https: //doi.org/10.1186/s40886-016-0015-8

[3] Alkorashy HAE, Al Moalad FB. Workplace violence against nursing staff in a Saudi university hospital. International Nursing Review. 2016; 63(2): 226-232. PMid:26830364 https://doi.org/10.1 111/inr. 12242

[4] Chang HE, Cho SH. Workplace violence and job outcomes of newly licensed nurses. Asian Nursing Research. 2016; 10(4): 271 276. PMid:28057313 https://doi.org/10.1016/j.anr. 2016 .09 .001

[5] Zainal N, Rasdi I, Saliluddin SM. The Risk Factors of Workplace Violence among Healthcare Workers in Public Hospital. 2018.

[6] Zhang SE, Liu W, Wang J, et al. Impact of workplace violence and compassionate behaviour in hospitals on stress, sleep quality and subjective health status among Chinese nurses: a crosssectional survey. BMJ Open. 2018; 8(10): e019373. PMid:30287664 https://doi.org/10.1136/bmjopen-2017-019373 establishing guidelines against verbal abuse in the workplace.

\section{Conclusion}

This study showed that Saudi nursing interns are exposed to and suffer from verbal abuse. Intern nurses are practicing their newly acquired knowledge for the very first time. Thus, the combination of working shifts, facing a high pressure work load, their insufficient exposure to patients, and lack of skill in comparison to more experienced colleagues, coupled with being subjected to verbal abuse, is likely to affect them negatively physiologically, psychologically, socially, and most importantly in continuity in the nursing profession. However, being aware of their rights, how to handle an event of abuse, and the procedures for reporting such an event will make them more confident when faced with verbal abuse.

\section{ACKNOWLEDGEMENTS}

We wish to send our gratitude and appreciation to the almighty Lord for providing us with the strength to complete this research. We are grateful to the doctors at the nursing college at King Abdul-Aziz University. Also, we are grateful to all the nursing interns who participated in this study. Finally, we want to express our gratitude to our families for always motivating and supporting us to achieve our goals, especially Mawaddah Batwa for continuous guidance and support.

\section{CONFlicts OF InTEREST Disclosure}

The authors declare that there is no conflict of interest.
[7] Lu L, Lok KI, Zhang L, et al. Prevalence of verbal and physical workplace violence against nurses in psychiatric hospitals in China. Archives of Psychiatric Nursing. 2019; 33(5): 68-72. PMid:31711597 https://doi.org/10.1016/j . apnu . 2019.07.002

[8] Silwal K, Joshi S. Verbal Abuse among Nurses in Tertiary Ca Hospitals. Journal of the Nepal Medical Association. 2019; 57(218) https://doi.org/10.31729/jnma.4571

[9] Tekin YE, Bulut H. Verbal, physical and sexual abuse status against operating room nurses in Turkey. Sexuality and Disability. 2014; 32(1): 85-97. https ://doi .org/10.1007/s11195-0 14-9339-7

[10] Al-Shamlan NA, Jayaseeli N, Al-Shawi MM, et al. Are nurses verbally abused? A cross-sectional study of nurses at a university hospital, Eastern Province, Saudi Arabia. Journal of Family \& Community Medicine. 2017; 24(3): 173. PMid:28932162 https://doi.org/10.4103/jf cm.JFCM_45_17

[11] Chang HE, Park MY, Jang H, et al. Relationships among demands at work, aggression, and verbal abuse among registered nurses in South Korea. Nursing Outlook. 2019; 67(5): 567-577. PMid:31202443 https://doi .org/10.1016/j.outlook. 2019.04.007

[12] Al-Omari H. Physical and verbal workplace violence against nurses in J ordan. International Nursing Review. 2015; 62(1): 111-118. 
PMid:25626758 https://doi.org/10.1111/inr.12170

[13] Ahmed AS. Verbal and physical abuse against Jordanian nurses in the work environment. 2012.

[14] Shdaifat EA, Al Amer MM, Jamama AA. Verbal abuse and psychological disorders among nursing student interns in KSA. Journal of Taibah University Medical Sciences. 2020; 15(1): 66. PMid:32110185 https://doi.org/10.1016/j.jtumed. 201 9.12 .007

[15] Zhang L, Wang A, Xie X, et al. Workplace violence against nurses: A cross-sectional study. International Journal of Nursing Studies. 2017; 72: 8-14. PMid:28412581 https://doi.org/10.1016/j.ijnu rstu.2017.04.002

[16] Cheung T, Yip PS. Workplace violence towards nurses in Hong Kong: prevalence and correlates. BMC public health. 2017; 17(1): 196. PMid:28196499 https://doi.org/10.1186/s12889-017 $-4112-3$

[17] Dimassi H, Alameddine M, Mourad Y. A National Study on Nurses' Exposure to Occupational Violence in Lebanon. 2015.

[18] Martino V. Workplace Violence in the Health Sector: Country Case Studies. Brazil, Bulgaria, Lebanon, Portugal, South Africa, Thailand and an Additional Australian Study. Geneva: World Health Organization; 2002.
[19] Kwok RP, Law YK, Li KE. Prevalence of workplace violence against nurses in Hong Kong. Hong Kong Medical Journal. 2006.

[20] Oweis A, Diabat K. Jordanian nurses perception of physicians verbal abuse: findings from a questionnaire survey. Interna-tional Journal of Nursing Studies. 2005

[21] Adib SM, et al. Al-Raqem M. Violence against nurses in healthcare facilities in Kuwait. International Journal of Nursing Studies. 2002

[22] Yoon SH. A study on graduate nurses' clinical experience of adaptation.J Korean Acad Nurs Admin. 2002; 8(1): 55e72. Korean.

[23] Roche M, Diers D, Duffield C, et al. Violence toward nurses, the work environment, and patient outcomes. J Nurs Sch. 2010; 42(1): 13e22. PMid:20487182 https://doi.org/10.1111/j.1547-5069.20 $09.01321 . x$

[24] Park M, Cho SH, Hong HJ. Prevalence and perpetrators of workplace violence by nursing unit and the relationship between violence and the perceived work environment. J Nurs Sch. 2015; 47(1): 87e95. PMid:25352254 https://doi.org/10.1111/jnu.12112

[25] Lin Y, Liu H. The impact of workplace violence on nurses in South Taiwan. International Journal of Nursing Studies. 2005; 42: 773-778. PMid:15964004 https://doi.org/10.1016/j.ijnurstu. 200 4.11 .010 